\title{
EM QUE A SOCIOLOGIA PODE CONTRIBUIR PARA A EDUCAÇÃO PROFISSIONAL E TECNOLÓGICA?
}

\author{
A. Oliveira \\ Universidade Federal de Alagoas \\ E-mail: amurabi_cs@hotmail.com
}

Artigo submetido em agosto/2013 e aceito em outubro/2013

\section{RESUMO}

Este trabalho visa desenvolver uma breve reflexão em torno do Ensino de Sociologia na Educação Profissional e Tecnológica, apontando para possíveis contribuições que essa ciência poderia trazer para a formação no Ensino Médio integrado ao Técnico. As questões aqui postas se desenvolvem tendo como substrato teórico principal as contribuições de Anthony Giddens, bem como considerando a finalidade da Sociologia no Ensino Médio.

PALAVRAS-CHAVE: Ensino de Sociologia; Educação Profissional e Tecnológica; Ciências Humanas.

\section{SOCIOLOGY IN WHICH CAN CONTRIBUTE TO PROFESSIONAL AND TECHNICAL EDUCATION?}

\section{ABSTRACT}

This paper aims to develop a brief reflection on the Teaching of Sociology in Vocational and Technological Education, pointing to possible contributions that science could bring to training in the Integrated
Technical High School. The questions put here develop as substrate main theoretical the contributions of Anthony Giddens, as well as considering the purpose of sociology in high school.

KEYWORDS: Sociology of Education, Vocational and Technological Education, Human Sciences. 


\section{EM QUE A SOCIOLOGIA PODE CONTRIBUIR PARA A EDUCAÇÃO PROFISSIONAL E TECNOLÓGICA?}

\section{INTRODUÇÃO}

Muito tem-se debatido em torno do retorno recente da Sociologia no currículo escolar, o que se deu por meio do Parecer CNE/CB no 38/06 e pela lei $n=11.684 / 08^{1}$, o que tem implicado em um número crescente de pesquisas que vem sendo desenvolvidas em nível de pósgraduação, em sua maioria concentradas em programas de Educação (HANDFAS, 2011). Todavia, no que diz respeito especificamente à Educação Profissional e Tecnológica - EPT a Sociologia possui uma história singular, marcada por encontros e desencontros, pois, enquanto na primeira metade do século XX a Sociologia compunha o currículo dos cursos complementares, voltados para a formação das elites que ingressariam nos cursos universitários (GUELFI, 2001), o ensino profissionalizante surge nesse mesmo período com outra finalidade, voltado justamente para as classes "menos privilegiadas", conforme preconizava a Constituição de 1937 (FREITAG, 1980). Mais que isso, os dois cursos de nível médio nesse período: o propedêutico e o técnico não se equivaliam, e este último não garantia ao aluno o direito de ingressar no ensino superior, o que foi superado apenas com a primeira LDB em 1961.

A educação profissional continuou a se desenvolver no Brasil, ao passo que a Sociologia após a Reforma Capanema em 1942 desapareceu dos currículos escolares, também é interessante destacar um outro momento de desenvolvimento opostos entre a Sociologia e a Educação Profissional que se deu no decorrer dos anos de 1970, quando é proposta a profissionalização compulsória do Ensino Médio no Brasil, que se vinculava ao alinhamento das políticas educacionais com os interesses internacionais que emergiam nesse momento, bem como havia naquele momento os interesses das elites nacionais associadas ao capital internacional. Segundo Schrader (2009, p. 84):

A introdução da formação profissional como objetivo educacional da escola significou atribuir ao ensino, para além da tarefa de preparar para a continuidade da escolaridade, também o objetivo de um valor próprio, ou seja, um a formação concluída.

Neste mesmo período a Sociologia continuou marginalizada no currículo escolar, transformada em Estudos Sociais, Educação Moral e Cívica e Organização Social e Política do Brasil (SILVA, 2007), ante a esse processo de profissionalização do Ensino Médio, na forma como foi concebido, não havia espaço para a reflexão sociológica, ainda que alguns conceitos e categorias continuassem a ser utilizados de forma dissolvida nessas outras disciplinas.

O fim do processo de profissionalização compulsória do Ensino Médio, por meio da lei no 7.044/82, demarcou o retorno gradual da Sociologia aos currículos escolares, o que se deu de forma pontual em alguns estados (SANTOS, 2004). Interessante perceber que concomitante a esse movimento a Sociologia começa a marcar presença também nos currículos das instituições

1 Neste texto não adentraremos na questão do histórico da Sociologia no currículo escolar, contudo, para uma melhor análise desta questão vide os trabalhos de Santos (2004), Silva (2010), Moraes (2011) e Oliveira (2013). 
que compõem a rede de Educação Profissional e Tecnológica - EPT, o que se acelera no decorrer dos anos de 1990, ainda que isso se dê normalmente com uma ou duas aulas semanais em um único ano do Ensino Médio Integrado ao Técnico. Esse período também é de profunda crise nessa rede, ao mesmo tempo em que se expandem os cursos de tecnologia de nível superior (MOURA, 2007), seguindo uma tendência mais ampla do Ensino Superior no Brasil que passa a ser capitaneado pela iniciativa privada (MARTINS, 2000).

Em todo o caso esta configuração cria uma situação aparentemente paradoxal, pois, por um lado, a Sociologia permanece ausente no currículo escolar, inclusive tendo sido vetada a sua reintrodução em 2001 pelo então presidente Fernando Henrique Cardoso, sociólogo ${ }^{2}$, por outro se faz presente no currículo das formações de Ensino Médio que compõem a Rede de EPT, ainda que de forma marginal.

O cenário que é inaugurado em 2008 com o processo de reintrodução da Sociologia no Ensino Médio ocorre de forma concomitante à transformação da maior parte dos Centros de Educação Tecnológica e Escolas Agrotécnicas Federais em Institutos Federais de Educação, Ciência e Tecnologia, e oferecendo estas instituições cursos de Ensino Médio Integrado ao Técnico deveriam se submeter também à legislação pertinente ao Ensino Médio regular, que nesse caso demarcava que as aulas de Sociologia, assim como as de Filosofia, deveriam estar presentes em todas as séries do Ensino Médio. Obviamente este não é um processo linear, e buscaremos no decorrer desse texto realizar uma breve reflexão sobre o lugar do Ensino de Sociologia nessa Rede de Ensino.

\section{OS SENTIDOS DE ENSINAR SOCIOLOGIA}

Faz-se necessário realizar uma breve incursão sobre os sentidos atribuídos ao Ensino de Sociologia, para tanto restringiremos nosso recorte às discussões que se desenvolvem após a Lei no 9.394/96, a atual LDB, que em seu artigo número 36 indica que os alunos egressos do Ensino Médio deveriam possuir conhecimentos de Sociologia e de Filosofia para o exercício da cidadania, com isso a LDB criou uma situação controversa, já que, buscou garantir o Ensino da Sociologia, mas não a sua existência enquanto disciplina escolar, o que estava em consonância com a perspectiva flexibilizante de currículo com o qual a LDB se alinhava (PINO, 2007), e que seria confirmado posteriormente pelas Diretrizes Curriculares para o Ensino Médio, uma vez que:

De acordo com as DCNEM, as escolas poderiam diluir os conhecimentos de
Sociologia nos conteúdos de outras disciplinas, mesmo porque, segundo a
concepção que sustentava tal parecer, tais disciplinas já contemplavam aqueles
conhecimentos e - certamente a principal razão - pretendia-se transitar para um
currículo o menos "disciplinarizado" possível, haja vista a organização por áreas
de conhecimentos que as Diretrizes propunham para a escola média. (MORAES,
2011, p. 370)

Percebamos que além desta questão a LDB traz um outro ponto, que diz respeito à ligação entre a Sociologia e o exercício para a cidadania. Tanto esta perspectiva flexibilizante quanto à

2 Para uma melhor análise vide Moraes (2004). 
ligação entre o Ensino de Sociologia e o exercício para a cidadania são confirmadas pelos Parâmetros Curriculares Nacionais: Conhecimentos de Sociologia, Antropologia e Política, publicados em 1999. Contudo, alguns pesquisadores têm questionado essa relação estabelecida, tendo em visa que:

Justificar a sociologia em virtude da formação para a crítica e para a cidadania pressupõe preparar os jovens para "um depois"; eles precisam aprender certos conteúdos para um dia exercer essas condições. E a escola não faz parte da trama social atual? Nela não se exerce a crítica e a cidadania? Argumentar a importância do conhecimento sociológico segundo aquele horizonte pode negar aos jovens a participação política; protela-se essa possibilidade em vista dos seus "desinteresses, descompromissos, apatias", como frequentemente são caracterizados por professores. (MOTA, 2005, p. 99)

Ou seja, o que poderia em princípio se apresentar como uma "nobre justificativa" para o Ensino dessa ciência se mostrou, em verdade, como um discurso vazio, pouco fundamentado e conservador, e que não se fazia claro nem mesmo para os docentes dessa disciplina, que apresentam concepções distintas sobre a ideia de cidadania. O que se deve, dentre outros fatores, a própria ausência de identidade do Ensino Médio, compreendido muitas vezes como uma mera etapa a ser superada para o ingresso no Ensino Superior, atrela-se a este cenário as próprias disputas existentes entre as disciplinas, tendo em vista que:

O currículo do ensino médio sempre foi um campo de disputa entre diferentes projetos sociais, que concorrem pela apropriação de parcela do conhecimento socialmente produzido, e entre distintos grupos profissionais, pelo seu potencial de ampliação da inserção no mercado de trabalho. (KRAWCZYK, 2011, p. 757)

Essas disputas encontram-se ainda mais acirradas na Educação Profissional, tendo em vista as tensões que se estabelecem no processo de formulação de um currículo de Ensino Médio integrado ao técnico.

Porém essa simplificação passa a ser profundamente questionada com a publicação das Orientações Curriculares Nacionais de Sociologia em 2006, quando se redireciona as finalidades da Sociologia nesse nível de ensino apontando para a produção do estranhamento e desnaturalização da realidade social, o que deveria ser realizado articulando-se os conceitos, temas e teorias, que deveriam ser completados com a pesquisa. Seguindo os passos propostos pelas OCN deveremos reconhecer que:

É contribuição das Ciências Sociais, como a disciplina Sociologia para o nível médio, propiciar aos jovens o exame de situações que fazem parte do seu dia a dia, imbuídos de uma postura crítica e atitude investigativa. É sua tarefa desnaturalizar os fenômenos sociais, mediante o compromisso de examinar a realidade para além de sua aparência imediata, informada pelas regras inconscientes da cultura e do senso comum. Despertar no aluno a sensibilidade para perceber o mundo à sua volta como resultado da atividade humana e, por isso mesmo, passível de ser modificado, deve ser a tarefa de todo professor. (MORAES, GUIMARÃES, 2010, p. 48) 
Considerando os aspectos idiossincráticos da formação de nível médio integrada à Educação Profissional cabe-nos reconhecer que esta possível contribuição da Sociologia se faz ainda mais necessária, tendo em vista que uma perspectiva reducionista da educação técnicoprofissional levaria a "Um caminho inverso, portanto, ao sentido mesmo de educação tecnológica enquanto base ou fundamento científico das diferentes técnicas e de formação humana nos campos social, político e cultural." (FRIGOTTO, 2007, p. 1140), e nesta direção, a Sociologia poderia abrir novas possibilidades no processo formativo contextualizando a produção do conhecimento e da ciência.

\section{ALGUMAS POSSÍVEIS CONTRIBUIÇÕES DA SOCIOLOGIA}

Um primeiro aspecto que é merecedor de destaque é o fato da Sociologia ser, por excelência, uma ciência que examina as sociedades modernas (GIDDENS, 1991), nas quais a ciência em seu processo reflexivo constitui elemento central. Ao contrário das sociedade prémodernas, nas quais o conhecimento possuía seus guardiões e possui uma verdade voltada para os iniciados, nas sociedade modernas há a formulação de um sistema perito, sintetizado na figura do especialista, no caso que estamos pensando aqui isto é especialmente emblemático, já que a educação profissional integrada ao Ensino Médio, para além de formar o sujeito de forma abstrata, visa também tornar esse sujeito em especialista em um dado saber. Para este especialista o conhecimento sociológico mostra-se fundamental, tendo em vista o próprio mundo no qual o seu conhecimento especializado está inserido, já que:

Mais que qualquer outra tarefa intelectual, a reflexão sociológica ocupa um papel central para a compreensão das forças sociais que vêm transformando nossas vidas nos dias de hoje. A vida social tornou-se episódica, fragmentária e marcada por novas incertezas, para cujo entendimento deve contribuir o pensamento sociológico criativo. (GIDDENS, 2001, p. 19).

Soma-se a tais questões o que é trazido por Santos (1995), ao pontuar que todo conhecimento é um conhecimento social, na medida em que é produzido em sociedade e para a sociedade. Sendo assim, formar técnicos é mais do que dotar os agentes sociais de um saber específicos sobre uma área do conhecimento, é necessário que eles saibam como esse conhecimento é produzido socialmente, em que contexto e com quais finalidades.

A ideia do Ensino de Sociologia voltado para a desnaturalização da realidade social ganha ainda mais sentido na Educação Profissional, tendo em vista que a própria relação existente entre o conhecimento científico e o processo de dominação ideológica, como já anunciado por Habermas (2009).

Atrela-se a tais questões a característica intrínseca da Sociologia que remete ao seu aspecto reflexivo, que diz respeito a sua possibilidade de renovar seu conhecimento continuamente mediante novos conhecimentos, o que, em nossa interpretação, traz uma contribuição substancial à realidade educacional, tendo em vista que:

A análise reflexiva da realidade social leva-nos a um processo de alteração posicional e cognitiva do sujeito educacional, processo que nos possibilita 
vislumbrar um papel mais ativo do agente ante a estrutura na modernidade. Desse modo, o mesmo poderia reavaliar suas próprias práticas e a conjuntura que se insere sempre à luz de uma nova reflexão e um novo conjunto de conhecimentos. (OLVEIRA, 2010b, p. 59).

Ou seja, acreditamos que a Sociologia é capaz de abrir novas possibilidades no processo formativo profissional, contextualizando o conhecimento técnico. Mais que isso, deve-se se reconhecer que a Educação Profissional encontra-se ligada diretamente ao processo de desenvolvimento da sociedade industrial, assim como a Sociologia, que pode contribuir para a crítica das formas existentes de sociedade, crítica está baseada em análises, que se mostram, por vezes, contrastantes (GIDDENS, 1984).

Além do mais a Sociologia traz ainda uma substancial contribuição na análise das relações de trabalho, em especial nas sociedades capitalistas, bem como do processo de globalização, ambas as questões possuem implicações diretas sobre a realidade da EPT, bem como sobre o campo de atuação posterior dos sujeitos formados pelos Institutos Federais.

Para Giddens (2005) a Sociologia pode ajudar os sujeitos por meio de três aspectos principalmente: a) a consciência das diferenças culturais, tendo em vista que ela nos possibilita ver o mundo a partir de outros pontos de vista que não o nosso exclusivamente; b) avaliando os efeitos das políticas, já que a pesquisa sociológica nos fornece elemento para a avaliação de iniciativas políticas; c) o auto esclarecimento, uma vez que "Quanto mais sabemos por que agimos como agimos e como se dá o completo funcionamento de nossa sociedade, provavelmente seremos mais capazes de influenciar nossos próprios futuros." (Ibidem, p. 27)

Tais questões mostram-se relevantes para o aluno da Rede Tecnológica, bem como para o aluno do Ensino Médio regular, acreditamos que no primeiro caso deve-se haver um esforço na direção de construir diálogos com a formação profissional do aluno, no sentido em que, a Sociologia deve dizer algo que substancialmente possa ser pensado como uma ferramenta de reflexão efetiva sobre determinada prática. Isso não quer dizer que os demais conhecimentos sociológicos não sejam válidos, muito pelo contrário, tendo em vista que os clássicos, por exemplo, nos lançaram questões que ainda nos são atuais e relevantes (ALEXANDER, 1999). Tal questão nos remete diretamente à questão do currículo integrado no qual:

No 'currículo integrado', conhecimentos de formação geral e específicos para o exercício profissional também se integram. Um conceito específico não é abordado de forma técnica e instrumental, mas visando a compreendê-lo como construção histórico-cultural no processo de desenvolvimento da ciência com finalidades produtivas. Em razão disto, no 'currículo integrado' nenhum conhecimento é só geral, posto que estrutura objetivos de produção, nem somente específico, pois nenhum conceito apropriado produtivamente pode ser formulado ou compreendido desarticuladamente das ciências e das linguagens. (RAMOS, 2006, p. 79).

Certamente que este feito se mostra como um desafio para todas as disciplinas que compõem um currículo integrado, porém, no caso da Sociologia deve-se ter em vista ainda a seguinte questão: 
[...] como sabemos, os atores sociais devem ter algum tipo de conhecimento acerca do funcionamento da vida social a fim de que possam viver em sociedade. Parafraseando Schütz, somos todos sociólogos espontâneos e, em parte, é essa "sociologia espontânea" que é trazida à consciência quando o contexto é enfatizado. Mas é preciso reconhecer que a sociologia é também um tipo de conhecimento especializado e relativamente opaco ao entendimento espontâneo da vida cotidiana (Durkheim, 1981), o que gera a necessidade de se estabelecer uma ruptura epistemológica entre o conhecimento do senso-comum e o conhecimento científico ou especializado (Bourdieu, 2004). Em termos mais próximos aos que utilizei anteriormente, o conhecimento do senso-comum deve ser estranhado e desnaturalizado por meio da abertura a um outro horizonte: 0 do conhecimento especializado da sociologia (HAMLIN, 2009, p. 77).

Ou seja, há ainda um desafio epistemológico claramente posto (OLIVEIRA, 2011), que escamoteia a prática pedagógica de Sociologia, contudo, a possibilidade de buscar uma "ruptura epistemológica" nos coloca diante de outras considerações interessantes que a Sociologia teria a acrescer à EPT, que diz respeito, justamente, à problematização e distinção entre senso-comum e saber científico, o que em nossa concepção é um elemento fundamental para a formação tecnológica.

Se consideramos que essa formação profissional vai para além da instrumentalização de um dado conhecimento, e mais que isso, se compreendemos "[...] a tecnologia como construção social complexa integrada às relações sociais de produção." (MOURA, PINHEIRO, 2009), perceberemos que a Sociologia mostra-se como uma peça fundamental no processo de consolidação plena da EPT (OLIVEIRA, 2010a), tendo em vista que as questões que ela traz, e sua problematização, se volta não apenas para o que lhe é particular, mas sim, para todo o currículo.

\section{CONSIDERAÇÕES FINAIS}

Dentro desse breve trabalho buscamos trazer algumas reflexões sobre o Ensino de Sociologia na Educação Profissional, destacando algumas contribuições que esta ciência pode trazer para esta realidade de ensino, todavia, devemos reconhecer que o currículo é sempre um território em disputa, e que o lugar que a Sociologia ocupa na rede de EPT varia não apenas de acordo com a concepção que é formulada em torno das Ciências Humanas, mas sim com a própria concepção do que é a tecnologia e o saber tecnológico.

Se por um lado hoje podemos verificar a existência de licenciaturas em Ciências Sociais junto a alguns Institutos Federais (PANSARDI, 2013), por outro é emblemático que ainda haja outros que realizam concursos conjuntos para professor de "Sociologia e Filosofia", o que indica um não reconhecimento da especificidade do conhecimento que será produzido junto aos alunos do Ensino Médio Integrado ao Técnico.

As questões aqui trazidas também poderão ser interpretadas como de maior ou menor relevância de acordo com os vários projetos em curso e em disputa da EPT, que transparece as concepções de diversos setores da sociedade em torno que entram em disputa (FRIGOTTO, CIAVATTA, RAMOS, 2005). 
Por fim, reafirmamos aqui a relevância que possui para o aluno que ingressa em um curso de formação profissional de compreender o seu lugar no mundo, o lugar do conhecimento que ele está operacionalizando, e para tal feito certamente a Sociologia possui uma contribuição inestimável.

\section{REFERÊNCIAS}

ALEXANDER, Jeffrey. A importância dos clássicos. In: GIDDENS, Anthony; TURNER, Jonathan (Org.). Teoria social hoje. São Paulo: Editora UNESP, 1999.

BRASIL. Orientações Curriculares Nacionais: sociologia. Brasília: MEC, 2006.

Parâmetros Curriculares Nacionais: conhecimento de sociologia, antropologia e política. Brasília: MEC, 1999.

FREITAG, Barbara. Escola, Estado e Sociedade. São Paulo: Moraes, 1980.

FRIGOTTO, Gaudêncio. A relação da educação profissional e tecnológica com a universalização da educação básica. Educação e Sociedade, v. 28, p. 1129-1152, 2007.

FRIGOTTO, Gaudêncio; CIAVATTA, Maria; RAMOS, Marise. A política de Educação Profissional no Governo Lula: Um percurso histórico controvertido. Educação e Sociedade, Campinas, v. 26, no 92, p. 1087-1113, 2005.

GIDDENS, Anthony. As Consequências da Modernidade. São Paulo: Editora UNESP, 1991.

Em Defesa da Sociologia. São Paulo: Editora UNESP, 2001.

Sociologia. Porto Alegre: Artmed, 2005.

Sociologia: uma breve porém crítica introdução. Rio de Janeiro: Zahar Editores, 1984.

GUELFI, Wanirley Pedroso. A Sociologia como disciplina escolar no Ensino Secundário brasileiro (1925-1942). 2001. 194 f. Dissertação (Mestrado em Educação) - Universidade Federal do Paraná, Curitiba, 2001.

HABERMAS, Jurgen. Técnica e Ciência como Ideologia. Lisboa: Edições 70, 2009.

HAMLIN, Cynthia Lins. Desenvolvendo uma Terceira Cultura nas Escolas: habitus sociológico, estranhamento e desnaturalização de preconceitos. Tomo, v. 15, p. 71-82, 2009.

HANDFAS, Anita. O estado da arte do ensino de sociologia na educação básica: um levantamento preliminar da produção acadêmica. Inter-legere, s/v, n. 9, p. 386-400, 2011.

KRAWCZK, Nora. Reflexão sobre alguns desafios do ensino médio no Brasil hoje. Cadernos de Pesquisa, vol.41, no.144, p.752-769. 2011.

MARTINS, Carlos Benedito C.O Ensino Superior Brasileiro nos anos 90. São Paulo em Perspectiva, v. 14 n. 1, p. 41-60, 2000.

MORAES, Amaury Cesar. Ensino de Sociologia: periodização e campanha pela obrigatoriedade. Cadernos CEDES, v. 31, p. 359-382, 2011.

O Veto de FHC: o sentido de um gesto. In: CARVALHO, Lejeune Mato Grosso de. (org.). Sociologia e Ensino em Debate: experiências e discussão de sociologia no ensino médio. ljuí: Ed. Unijuí, 2004. p. 105-111. 
MORAES, Amaury C; Guimarães, Elisabeth F. Metodologia de Ensino de Ciências Sociais: relendo as OCEM-Sociologia. In: MORAES, Amaury Cesar (Org.). Sociologia: ensino médio. Brasília: MEC/SEB, 2010, v. 15, p. 45-62.

MOURA, Dante Henrique. Educação Básica e Educação Profissional e Tecnológica: dualidade histórica e perspectivas de integração. Holos, v. 23, n. 2, p. 4-30, 2007.

MOURA, Dante Henrique; PINHEIRO, Rosa Aparecida. Currículo e formação humana no ensino médio técnico integrado de jovens e adultos. Em Aberto, v. 22, n. 82, p. 91-108, 2009.

MOTA, Kelly Cristine Corrêa da Silva. Os lugares da sociologia na formação de estudantes do ensino médio: as perspectivas de professores. Rev. Bras. Educ. no.29, p.88-107. 2005.

OLIVEIRA, Amurabi. Ensino de Sociologia: Desafios epistemológicos para o ensino médio. Revista Espaço Acadêmico, v. 10, n. 119, p. 115-121, 2011.

Para que Serve Sociologia? Itinerários na Rede de Educação Profissional e Tecnológica. Tecnologia \& Cultura, v 12, n 16. p. 22-29, 2010a.

Revisitando a História do Ensino de Sociologia na Educação Básica. Acta Scientiarum. Education vol. 35, n 2, 2013.

Sociologia do Ensino de Sociologia no Brasil: Contribuições a partir de Anthony Giddens. Inter-ação, v. 35, p. 53-62, 2010 b.

PANSARDI, Marcos Vinícius. Um Estranho no Ninho: a formação de professores em sociologia nos Institutos Federais. Inter-Legere. s/v, n. 13, p. 235-249, 2013.

PINO, Ivani. A lei de diretrizes e bases da educação: a ruptura do espaço social e a organização da educação nacional. In: BRZEZINSKI, Iria (org.). LDB interpretada: diversos olhares se entrecruzam. São Paulo: Cortez, 2007. p. 19-39.

RAMOS, Marise Nogueira. Currículo Integrado - Verbete. In: Escola Politécnica de Saúde Joaquim Venâncio - FIOCRUZ. (Org.). Dicionário da Educação Profissional em Saúde. Rio de Janeiro: EPSJV/FIOCRUZ, 2006, p. 77-80.

SANTOS, Boaventura de Sousa. Um Discurso sobre as Ciências. Porto: Edições Afrontamento, 1995.

SANTOS, Mário Bispo. A Sociologia no Contexto das Reformas do Ensino Médio. In: CARVALHO, Lejeune Mato Grosso de. (org.). Sociologia e Ensino em Debate: experiências e discussão de sociologia no ensino médio. ljuí: Ed. Unijuí, 2004. p. 131-180.

SCHRADER, Achim. O Sistema Brasileiro de Educação no Período das Reformas após 1971. ljuí: Editora Unijuí, 2009.

SILVA, Ileizi L. F. O Ensino das Ciências Sociais/Sociologia no Brasil: histórico e perspectivas. In: MORAES, Amaury Cesar de (Org.). Coleção Explorando o Ensino de Sociologia. Brasília: MEC, 2010, p. 23-31.

A Sociologia no ensino médio: desafios institucionais e epistemológicos para a consolidação da disciplina. Cronos, v. 8, p. 403- 427, 2007. 